\title{
Editorial
}

\section{LA INVESTIGACIÓN CIENTÍFICA ES UNA ESTRATEGIA DE APRENDIZAJE ACTIVO EN LA FORMACIÓN DE PROFESIONALES UNIVERSITARIOS}

\author{
Dra. Aydeé de Parada \\ Directora de Investigación \\ Universidad Evangélica de El Salvador \\ aydee.rivera@gmail.com \\ https://orcid.org/0000-0002-1846-7157
}

El desarrollo de una cultura de investigación científica, sigue siendo una necesidad apremiante en el sistema educativo salvadoreño. Actualizar la metodología de enseñanza y de aprendizaje es un factor importante para que los estudiantes desarrollen pensamiento crítico y creativo para perfilar el ciudadano propositivo garante del desarrollo. La Ley de Educación Superior vigente (LES) promueve el desarrollo de investigación en todas sus formas y define la investigación como: «La investigación es la búsqueda sistemática y análisis de nuevos conocimientos para enriquecer la realidad científica, social y ambiental, así como para enfrentar los efectos adversos del Cambio Climático» (Art.3, LES).

La investigación científica es una estrategia de aprendizaje activo en la formación de profesionales universitarios, promueve el desarrollo del pensamiento crítico, científico y reflexivo; por ello, forma parte de las estrategias didácticas implementadas desde el modelo pedagógico en la Universidad Evangélica de El Salvador. La estrategia de aprendizaje basada en investigación se aplica tanto a la formación en cátedra, como en el proceso de grado que cierra el ciclo de formación profesional.

De tal manera que la enseñanza basada en la investigación se fortalece en la medida que los docentes mejoran las competencias científicas en la metodología científica y la profundización en el conocimiento disciplinar. Entre las estrategias de enseñanza se utiliza el Aprendizaje Basado en Problemas o Aprendizaje Basado en Proyectos; la primera, permite el estudio y análisis crítico de los problemas que enfrenta la comunidad, un sector 
o la población; el segundo, avanzar en la intervención y aporte directo a la solución de dichos problemas. Cuando los estudiantes son partícipes de las estrategias de aprendizaje basadas en la experiencia, sus niveles de desarrollo solidario son más sensibles a las necesidades colectivas. De la misma manera, se busca que las competencias de los docentes tengan cada vez un nivel mayor de investigación, publicación y trasferencia de conocimiento con los interesados y con los tomadores de decisiones.

De acuerdo con lo anterior, el proceso de formación tiene el propósito de perfilar la calidad científica para, finalmente, obtener productos de investigación pertinentes, que aporten a la búsqueda de soluciones de los problemas de país. Así se ha desarrollado en algunas universidades que buscan la mejora continua en investigación científica.

A nivel de país se han realizado algunas propuestas de promoción de la investigación científica, desde los centros educativos, pero aun es incipiente. En cuanto a la Política de Educación Superior, creada por primera vez en El Salvador, pretende el trabajo colaborativo y horizontal entre las IES salvadoreñas. Asimismo, tiene como principal objetivo promover el desarrollo social del país, en la búsqueda de «desarrollar sociedad del conocimiento comprometida con el bien común y la excelencia, que asegure la legitimidad de la institucionalidad y los recursos necesarios» (Política de Educación Superior, 2021).
En cuanto al tema de gobernanza toma en cuenta la articulación de las principales funciones de la Educación Superior, es decir, la docencia con la investigación y proyección social; la calidad y pertinencia de la educación superior y la accesibilidad; la equidad y eficiencia en la educación superior, así como el desarrollo profesional académico.

De igual modo, la articulación de las funciones enfatiza la práctica de transferencias de resultados de la investigación, procurando lazos de colaboración entre la academia, el sector productivo y el Gobierno, como actores importantes para promover el sistema nacional de innovación, integrar la proyección social con verdadero sentido de incorporar la ciencia, la tecnología y la innovación para la búsqueda del bienestar común, con especial énfasis en los grupos vulnerables que muestran que tienen limitadas oportunidades de desarrollo.

Por otra parte, la política considera cinco ejes fundamentales para organizar la estructura de Sistema Nacional de Educación Superior, para lograr la articulación de la docencia, la investigación y la proyección social: un eje que establece las normativas de calidad de la educación superior, otro eje, para procurar la accesibilidad, equidad y eficiencia de la educación superior y, finalmente, un eje que procura el desarrollo profesional académico. 
En la política se retoma la calidad y la pertinencia de la educación superior como un concepto complejo, relativo y multidimensional, para referirse al quehacer de las instituciones. También se promueve la pertinencia de la oferta formativa que abone al desarrollo innovador del país.

\section{(...) el concepto de calidad está asociado a la búsqueda de la excelencia, entendida como la adecuación de la formación académica y de la investigación a las necesidades sociales.}

Para ello, se requiere una visión de proceso continuo, en donde el aprendizaje institucional y personal se desarrolle a lo largo del tiempo y en función de los cambios que el contexto y la realidad del país demanden. (Política de Educación Superior, 2021)

En relación con la pertinencia, la política pretende contribuir al alcance de los Objetivos de Desarrollo Sostenible como un compromiso de país. Hace especial énfasis en el acceso iguali- tario a la formación técnica y a eliminar las disparidades de género e ingresos, así como lograr el acceso universal a una educación superior de calidad. Además, enfatiza la armonización de las IES con las políticas públicas, en cuanto a que las IES deben formar parte del desarrollo productivo, a nivel de región, de sectores o de comunidades, integrando las necesidades sociales con el sistema de valores y con procesos de desarrollo internacionales.

Por todo esto, como lo considera la nueva política de educación superior, la Universidad Evangélica promueve la actualización de estrategias para avanzar en el nivel de competencias científicas de los estudiantes y de su cuerpo docente a escala nacional, regional e internacional; la transferencia y aplicación de conocimiento. De igual manera la publicación científica va mejorando calidad, adquiriendo indexaciones en bases de datos de mayor reconocimiento, tal es el caso de la Revista científica Ciencia Cultura y Sociedad. 